\title{
High Dose-Rate Brachytherapy in Recurrent High-Risk Head and Neck
}

\section{Cancer}

\author{
Tanvir Pasha ${ }^{1}$, Siddanna Rudrappa Palled ${ }^{1,{ }^{*}}$, Rahul Loni ${ }^{1, * *}$, Shwetha Bondel ${ }^{2}$, Purushottam Chavan ${ }^{3}$, \\ Ashok Shenoy ${ }^{3}$, Thimmaiah Naveen ${ }^{1}$ and V Lokesh ${ }^{1}$ \\ ${ }^{1}$ Radiation Oncology, Kidwai Memorial Institute of Oncology, Bangalore, India \\ ${ }^{2}$ Radiation Physics, Kidwai Memorial Institute of Oncology, Bangalore, India \\ ${ }^{3}$ Head and Neck Oncology, Kidwai Memorial Institute of Oncology, Bangalore, India \\ "Corresponding author: Department of Radiation Oncology, Kidwai Memorial Institute of Oncology, Bangalore-29, India. Tel: +91-9980666727, Email: siddannap@gmail.com \\ "* Corresponding author: Department of Radiation Oncology, Kidwai Memorial Institute of Oncology, Bangalore-29, India. Tel: +91-8123782187, Email: drrahulloni@gmail.com \\ Received 2019 September 25; Accepted 2019 November 27.
}

\begin{abstract}
Background: Thirty to fifty percent of HNSCC patients treated with chemoradiation therapy present with recurrence and can be treated with maximum debulking surgery combined with re-irradiation. Re-irradiation can be done using external beam radiation therapy (EBRT) or brachytherapy. The advantage of brachytherapy over EBRT is that owing to rapid dose falls off, a higher dose can be delivered to the target area sparing normal tissue. Hence, we evaluated toxicity and outcomes [overall survival (OS) and diseasefree survival(DFS)] in high-risk(HR) recurrent HNSCC patients undergoing re-irradiation using interstitial brachytherapy following surgery.

Objectives: To evaluate toxicity and outcomes of re-irradiation using Interstitial High Dose-Rate Brachytherapy (HDR-BRT) in highrisk Head and Neck Squamous Cell Carcinoma (HNSCC) patients.

Methods: Ten biopsy-proven recurrent HNSCC patients treated with primary chemoradiation therapy who had the HR of the second recurrence at nodal disease were evaluated. All patients underwent surgery followed by the intraoperative placement of catheters in a single plane, at $10-12 \mathrm{~mm}$ apart and fixed with stay sutures. The CT simulation was done on the 5th - 7th postoperative day. Volumetric optimization was done with a 5-mm dwell position. The dose of $30 \mathrm{~Gy} / 10$ Fractions, $3 \mathrm{~Gy} / \mathrm{Fraction}$, two fractions per day, 6 hours apart after 5 days was planned.

Results: The DFS and OS for the entire cohort in 1 and 2 years were $60 \%$ and $40 \%$, respectively. One patient had carotid blowout where the disease was stuck to the carotid vessel. No other significant acute or late toxicity was noted.

Conclusions: The HDR-interstitial brachytherapy in the recurrent HR, HNSCC with the intraoperative placement of catheters at tumor bed provides reasonably good local control without significant acute or late toxicity.
\end{abstract}

Keywords: Re-Irradiation, Interstitial Brachytherapy, Recurrent Head and Neck Squamous Cell Cancer, High Dose-Rate Brachytherapy

\section{Background}

Approximately 600,000 patients afflict annually with head and neck squamous cell carcinoma (HNSCC) worldwide (1). At the present time, locally advanced HNSCC (LAHNSCC) without metastasis is seen in sixty percent of patients. The most common pattern of recurrence is a locoregional failure, and most fatalities result from uncontrolled loco-regional or local disease. The preferred primary treatment approach for LAHNSCC patients is surgery with radiation therapy or chemo-radiation therapy. In $\mathrm{HN}$ SCC patients treated with radical intent, the recurrence is seen in $30 \%-50 \%$ of the patients $(2,3)$.

Better local control can be achieved with maximum de- bulking surgery combined with a primary or a second new course of radiation therapy. External Beam Radiotherapy (EBRT) or High Dose-Rate Brachytherapy (HDR-BRT) can be used to deliver radiation therapy. Owing to the difficulty to spare adjacent normal tissues, which leads to undesirable late effects on the salivary glands, mandible, muscles of mastication, and serial structure spinal cord, reirradiation for recurrent disease using EBRT is always challenging. In these cases, the use of intra-operative interstitial implantation is an option, as it is ideally suited to deliver a high dose to a limited volume with minimizing dose to normal structure due to rapid dose fall-off thus minimizing sequelae and improving local control (4). Also,

Copyright (c) 2019, Reports of Radiotherapy and Oncology. This is an open-access article distributed under the terms of the Creative Commons Attribution-NonCommercial 4.0 International License (http://creativecommons.org/licenses/by-nc/4.0/) which permits copy and redistribute the material just in noncommercial usages, provided the original work is properly cited. 
HDR-BRT can increase total biological effective dose administered compared to the second course of EBRT, with decreased overall treatment time (5).

\section{Objectives}

Hence the feasibility in terms of toxicity and outcome of surgery followed by intraoperative interstitialbrachytherapy in recurrent head and neck cancer was studied.

\section{Methods}

Institutional Medical Ethics Review Board approved the study protocol and consent procedure. Informed consent was taken. Ten biopsy-proven HNSCC patients with a mean age of 47 years (range 36 - 65 years) were analyzed. Surgery followed by chemoradiation therapy was given in $33 \%$ (3) of the patients and chemoradiation was given with cisplatin (weekly $40 \mathrm{mg} / \mathrm{m}^{2}$ ) in 77\% (7) of the patients. Prebrachytherapy patient characteristics are shown in Table 1.

Before re-irradiation, all patients were evaluated for eligibility and the following selection criteria were applied: histologic evidence of disease relapse, Karnofsky performance score (KPS) $\geq 80$, no bony invasion by the tumor, and no evidence of distant metastases. These patients were at high risk of the second recurrence in view of a fixed node to the underlying structure.

Ten patients with locoregional recurrent disease underwent surgery followed by interstitial brachytherapy. Eight patients had neck nodal recurrence, which was stuck to the underlying structures and hence was considered high risk for recurrence even after surgical resection. Two patients with soft tissue recurrences at the BOT and Vallecula were considered for volume implant, where surgical clear margins were difficult to achieve. Nodal recurrence patients underwent Radical neck dissection (RND) and intraoperative catheter placement in the tumor bed in a single plane at 10 - $12 \mathrm{~mm}$ apart and stay sutures were placed to retain the catheters in their position. Subsequently, CT simulation with a slice thickness of $2.5 \mathrm{~mm}$ was performed on 5 th or 7 th postoperative day depending on the healing of surgical wounds. Major vessels of the neck were taken as organs at risk. Volumetric optimization method was used for planning with $5 \mathrm{~mm}$ dwell positions. Dwell timings over carotid vessels were minimized to prevent hyper dose sleeve. The dose of $30 \mathrm{~Gy} / 10$ fractions, $3 \mathrm{~Gy} /$ fraction, twice-daily fractions with 6 hours apart over 5 days was prescribed. Details of re-irradiation and implant characteristics are depicted in Table 2.

\begin{tabular}{|c|c|}
\hline Characteristics & No. $(\%)$ \\
\hline \multicolumn{2}{|l|}{ Gender } \\
\hline Male & $10(100)$ \\
\hline \multicolumn{2}{|l|}{ Age, $y$} \\
\hline Median & 45 \\
\hline Range & $30-65$ \\
\hline \multicolumn{2}{|l|}{ Primary tumor and LN stage } \\
\hline $\mathrm{T} 2$ & $4(40)$ \\
\hline T3 & $6(60)$ \\
\hline No & $1(10)$ \\
\hline N2 & $9(90)$ \\
\hline \multicolumn{2}{|l|}{ Primary tumor site } \\
\hline Oropharynx & $2(20)$ \\
\hline Hypopharynx & $4(40)$ \\
\hline Oral cavity & $3(30)$ \\
\hline Parotid & $1(10)$ \\
\hline \multicolumn{2}{|c|}{ Primary treatment (before implantation) } \\
\hline EBRT + chemotherapy & $6(60)$ \\
\hline Surgery + EBRT & $3(30)$ \\
\hline Surgery + EBRT + chemotherapy & $1(10)$ \\
\hline \multicolumn{2}{|l|}{ Radiation dose } \\
\hline Median & 66 \\
\hline Range & $60-70$ \\
\hline \multicolumn{2}{|l|}{ Time to relapse } \\
\hline Median, mo & 12.1 \\
\hline Range & $6-71$ \\
\hline \multicolumn{2}{|c|}{ Table 2. Details of Recurrent Disease and Implant Characteristics $(\mathrm{N}=10)$} \\
\hline Characteristics & No. (\%) \\
\hline HD-RBRT alone & $1(10)$ \\
\hline Surgery + HD-RBRT & $9(90)$ \\
\hline \multicolumn{2}{|l|}{ Implant location } \\
\hline Neck & $10(100)$ \\
\hline \multicolumn{2}{|l|}{ Re-irradiation dose } \\
\hline For all patients & $30 \mathrm{~Gy} / 10 \mathrm{fr}$ \\
\hline
\end{tabular}

\subsection{Follow-Up}

Overall follow-up ranged from 31 to 71 months (median 41 months) for survivors. Four patients reached a one-year follow-up. Two patients reached the three-year follow-up, 1 patient reached 5-year follow-up and 3 patients were alive at the time of reporting in April 2019. 


\section{Results}

Statistical analysis was done using ' $\mathrm{R}$ ' software ver.3.6.1 to calculate overall survival (OS) and disease-free survival (DFS).

\subsection{Local Control}

Over a median follow-up of 14 months, six patients developed local recurrence and one patient developed distant metastasis. The disease-free survival rates for the entire group in 1 and 2 years were $60 \%$ and $40 \%$, respectively.

\subsection{Overall Survival}

The OS rate for the entire group was $60 \%$ and $40 \%$ in 1 and 2 years, respectively.

\subsection{Toxicity}

One patient had carotid blow-out who had disease stuck to the carotid and was managed with carotid embolization and doing well till today. Remaining 9 (90\%) patients had grade I/II toxicity.

\section{Discussion}

Better local control can be achieved with debulking surgery in combination with primary radiation therapy or re-irradiation in recurrent loco-regional disease. In recurrent diseases, which are not amenable to surgery a low response rate of $50 \%-60 \%$ and a median survival of $5-6$ months is seen with chemotherapy $(6,7)$.

Re-irradiation using external beam therapy (EBRT) is limited by normal tissue complications caused by cumulative radiation doses. In RTOG 96-10, patients treated with EBRT and concurrent chemotherapy (5-fluorouracil and hydroxyurea) showed an overall survival of $41.7 \%$ and $16.2 \%$ at one and two years, respectively, with $7 \%$ grade $V$ toxicity and $23 \%$ grade IV acute toxicity (8). In the RTOG 96-11 phase II trial of hyper-fractionated EBRT with cisplatin and paclitaxel, the OS at one and two years were 50.2\% and $25.9 \%$, respectively. The incidence of grade $\mathrm{V}$ toxicity was $8 \%$ and $23 \%$ was reported for grade IV acute toxicity. Osteonecrosis was noted in $5 \%$ of the patients (9). In our study, one (10\%) patient had carotid blowout who had the disease stuck to carotid and remaining 9 (90\%) patients had grade I/II toxicity.

Both trials showed high-grade IV and V toxicities for re-irradiation with EBRT. But toxicity may be reduced with the use of newer techniques like intensity-modulated radiotherapy (IMRT) for re-irradiation in recurrent HNSCC. Sulman et al. and Duprez et al. have reported OS of 35\% to
$58 \%$ at two years and LC of $64 \%$ to $65 \%$, with $13 \%$ - $20 \%$ toxicity rate $(10,11)$. Roh et al. and Unger et al. reported $30 \%$ to $30.9 \%$ of OS and $41 \%$ to $52 \%$ of LC in 2 years, respectively, with late severe toxicity rate of $8.6 \%$ to $11 \%$ for re-irradiation using fractionated stereotactic radiotherapy $(12,13)$.

Recurrent head and neck cancers are less radioresponsive compared to primary non-irradiated cancer. Therefore, surgery followed by a sufficient dose of irradiation must be delivered to the treatment of a recurrent tumor. Using Brachytherapy high doses of radiation can be delivered to the tumor bed along with sparing the surrounding normal tissues. In our study, we could achieve local control as well as os of $60 \%$ and $40 \%$ at one and two years, respectively, without significant acute or late toxicities.

The review of the literature shows that two-year local control of $31 \%-69 \%$ and overall survival of $13 \%-57 \%$ can be achieved with Low Dose-Rate Brachytherapy (LDR-BRT) in recurrent head and neck cancer (14-18).

Better dose distribution, dose homogeneity within the target area and radiation safety and patient comfort can be obtained with HDR-BRT compared to LDR-BRT. There are only a few retrospective studies published on the role of HDR-BRT in recurrent HNSCC (19-22). A study done by Hepel et al. in which 30 patients with recurrent head and neck carcinoma were treated with two daily fractions of 3 - 4 Gy to a mean dose of $34 \mathrm{~Gy}$ (18 - 48Gy) showed local control rate of $54 \%$ and $45 \%$ and overall survival of $56 \%$ and $37 \%$, respectively in 1 and 2 years. Nineteen percent non-cancer related deaths were noted (19). Tselis et al. showed OS and DFS rates of $42 \%, 19 \%, 6 \%$, and $42 \%, 37 \%, 19 \%$, respectively at $1,2,3$ years in patients treated with HDR-BRT with a median dose of $30.0 \mathrm{~Gy}(12.0$ - 36.0) Gy delivered at twice-daily fractions of 2 - 5 gray (21). A study on hyper fractionated interstitial HDR-BRT by Kolotas et al. in which patients received twicedaily fractions of $3 \mathrm{~Gy} /$ fraction to a total dose of $30 \mathrm{~Gy}$ in 37 of 49 patients and 36 gray in 12 of 49 patients showed local control rate of $69 \%$ and OS rate of $52 \%, 31 \%, 6 \%$ at $1,2,3$ years, respectively (22). In another study done by Narayana et al., 30 patients were included in which 18 patients were treated with HDR-BRT using 3.4 Gy/fractions, two fractions per day to a total dose of 34 Gy followed by surgery, nine patients received HDR-BRT alone at $40 \mathrm{~Gy}$ (4 Gy/fraction two fractions per day) and three patients were treated with EBRT (40 - 50 Gy) and HDR-BRT (20 Gy, 4 Gy bid). The entire group showed an OS and local control of $63 \%$ and $71 \%$, respectively in 2 years (20). In all HDR-BRT studies, the majority of patients were treated with daily fractions of $3 \mathrm{~Gy}$ for a total dose of $30 \mathrm{~Gy}$ or $4 \mathrm{~Gy}$ for a total dose of $40 \mathrm{~Gy}$.

In our study, we could achieve a DFS of $60 \%$ and $40 \%$ in 1 and 2 years and OS of $60 \%$ and $40 \%$ in 1 and 2 years, respectively, with no significant acute or late toxicity even though 
nodes were stuck to tumor bed in our patients because they were at a high risk for the second recurrence. Six (60\%) patients were locally controlled in 1 year. One patient had carotid blow-out who had disease stuck to the carotid vessel and was managed with carotid embolization. Hence, carotid should be carefully delineated and doses should be restricted with no hyper dose sleeve falling on carotids in the re-irradiation setting.

\subsection{Conclusions}

HDR interstitial brachytherapy in recurrent high-risk head and neck cancers with intraoperative placement of catheters at the tumor bed provides excellent local control by precisely defining the target volumes and conformal coverage of the target.

\section{Footnotes}

Authors' Contribution: Tanvir Pasha developed the original idea and the protocol, abstracted and analyzed data, wrote the manuscript, and is the guarantor. Siddanna Rudrappa Palled and Rahul Loni, Shwetha Bondel, Purushottam Chavan, Ashok Shenoy, Thimmaiah Naveen, V Lokesh have contributed to the development of the protocol, abstracted data, preparation of the manuscript and statistical analysis.

Conflict of Interests: The authors have no conflict of interest to disclose.

Ethical Approval: Institutional Medical Ethics Review Board approved the study protocol and consent procedure.

\section{Funding/Support: None.}

Informed Consent: Informed consent was taken before the study.

\section{References}

1. Bray F, Ferlay J, Soerjomataram I, Siegel RL, Torre LA, Jemal A. Global cancer statistics 2018: GLOBOCAN estimates of incidence and mortality worldwide for 36 cancers in 185 countries. CA Cancer J Clin. 2018;68(6):394-424. doi:10.3322/caac.21492. [PubMed: 30207593].

2. Brockstein B, Haraf DJ, Rademaker AW, Kies MS, Stenson KM, Rosen F, et al. Patterns of failure, prognostic factors and survival in locoregionally advanced head and neck cancer treated with concomitant chemoradiotherapy: A 9-year, 337-patient, multi-institutional experience. Ann Oncol. 2004;15(8):1179-86. doi: 10.1093/annonc/mdh308. [PubMed: 15277256].

3. Pignon JP, le Maitre A, Maillard E, Bourhis J, Mach-Nc Collaborative Group. Meta-analysis of chemotherapy in head and neck cancer (MACH-NC): An update on 93 randomised trials and 17,346 patients. Radiother Oncol. 2009;92(1):4-14. doi: 10.1016/j.radonc.2009.04.014. [PubMed: 19446902].

4. Mazeron JJ, Noel G, Simon JM, Racadot S, Jauffret E. [Brachytherapy in head and neck cancers]. Cancer Radiother. 2003;7(1):62-72. French. doi: 10.1016/s1278-3218(02)00286-x. [PubMed: 12648718].
5. Novaes PERS, Gentil AC, Lima Jr CGB, Pellizzon ACA, Kowalski LP. Possibilities of high dose rate brachytherapy on treatment of head and neck cancer. 17th International Cancer Congress. Monduzzi Editori (International Proceedings Division) Bologna; 1998. p. 537-40.

6. Forastiere AA, Metch B, Schuller DE, Ensley JF, Hutchins LF, Triozzi P, et al. Randomized comparison of cisplatin plus fluorouracil and carboplatin plus fluorouracil versus methotrexate in advanced squamouscell carcinoma of the head and neck: A Southwest Oncology Group study. J Clin Oncol. 1992;10(8):1245-51. doi: 10.1200/JCO.1992.10.8.1245. [PubMed: 1634913].

7. Hong WK, Bromer R. Chemotherapy in head and neck cancer. $N$ Engl J Med.1983;308(2):75-9. doi: 10.1056/NEJM198301133080204. [PubMed: 6183588].

8. Spencer SA, Harris J, Wheeler RH, Machtay M, Schultz C, Spanos W, et al. RTOG 96-10: Reirradiation with concurrent hydroxyurea and 5-fluorouracil in patients with squamous cell cancer of the head and neck. Int J Radiat Oncol Biol Phys. 2001;51(5):1299-304. doi: 10.1016/s0360-3016(01)01745-x. [PubMed: 11728690].

9. Horwitz EM, Harris J, Langer CJ, Nicolaou N, Kies M, Curran WJ, et al. Phase II study of paclitaxel and cisplatin in combination with split course concomitant hyperfractionated re-irradiation in patients with recurrent squamous cell cancer of the head and neck: Results of RTOG 99-11. Int J Radia Oncol Biol Phys. 2005;63:S72-3. doi 10.1016/j.ijrobp.2005.07.125.

10. Sulman EP, Schwartz DL, Le TT, Ang KK, Morrison WH, Rosenthal DI et al. IMRT reirradiation of head and neck cancer-disease control and morbidity outcomes. Int J Radiat Oncol Biol Phys. 2009;73(2):399-409. doi: 10.1016/j.ijrobp.2008.04.021. [PubMed: 18556144].

11. Duprez F, Madani I, Bonte K, Boterberg T, Vakaet L, Derie C, et al. Intensity-modulated radiotherapy for recurrent and second primary head and neck cancer in previously irradiated territory. Radiother Oncol. 2009;93(3):563-9. doi: 10.1016/j.radonc.2009.10.012. [PubMed: 19919885].

12. Roh KW, Jang JS, Kim MS, Sun DI, Kim BS, Jung SL, et al. Fractionated stereotactic radiotherapy as reirradiation for locally recurrent head and neck cancer. Int J Radiat Oncol Biol Phys. 2009;74(5):1348-55. doi: 10.1016/j.ijrobp.2008.10.013. [PubMed: 19117695].

13. Unger KR, Lominska CE, Deeken JF, Davidson BJ, Newkirk KA, Gagnon GJ, et al. Fractionated stereotactic radiosurgery for reirradiation of head-and-neck cancer. Int J Radiat Oncol Biol Phys. 2010;77(5):1411-9. doi: 10.1016/j.ijrobp.2009.06.070. [PubMed: 20056341].

14. Housset M, Barrett JM, Brunel P, Delanian S, Rozec C, Maulard C, et al. Split course interstitial brachytherapy with a source shift: The results of a new technique for salvage irradiation in recurrent inoperable cervical lymphadenopathy greater than or equal to $4 \mathrm{~cm}$ diameter in 23 patients. Int J Radiat Oncol Biol Phys. 1992;22(5):1071-4. doi: 10.1016/0360-3016(92)90810-5. [PubMed: 1555955].

15. Bollet MA, Lapeyre M, Marchal C, Hoffstetter S, Peiffert D, Cornes PG, et al. Cervical lymph node relapses of head-and-neck squamous cell carcinoma: Is brachytherapy a therapeutic option? Int J Radiat Oncol Biol Phys. 2001;51(5):1305-12. doi: 10.1016/s0360-3016(01)01725-4. [PubMed: 11728691].

16. Kupferman ME, Morrison WH, Santillan AA, Roberts D, Diaz EJ, Garden AS, et al. The role of interstitial brachytherapy with salvage surgery for the management of recurrent head and neck cancers. Cancer. 2007;109(10):2052-7. doi:10.1002/cncr.22648. [PubMed: 17407106].

17. Cornes PG, Cox HJ, Rhys-Evans PR, Breach NM, Henk JM. Salvage treatment for inoperable neck nodes in head and neck cancer using combined iridium-192 brachytherapy and surgical reconstruction. BrJSurg.1996;83(11):1620-2. doi:10.1002/bjs.1800831141. [PubMed: 9014691].

18. Puthawala A, Nisar Syed AM, Gamie S, Chen YJ, Londrc A, Nixon V. Interstitial low-dose-rate brachytherapy as a salvage treatment for recurrent head-and-neck cancers: Long-term results. Int I Radiat Oncol Biol Phys. 2001;51(2):354-62. doi: 10.1016/s0360-3016(01)01637-6. [PubMed 11567809]. 
19. Hepel JT, Syed AM, Puthawala A, Sharma A, Frankel P. Salvage high-dose-rate (HDR) brachytherapy for recurrent head-andneck cancer. Int J Radiat Oncol Biol Phys. 2005;62(5):1444-50. doi: 10.1016/j.ijrobp.2004.12.078. [PubMed:16029806].

20. Narayana A, Cohen GN, Zaider M, Chan K, Lee N, Wong RJ, et al. High-dose-rate interstitial brachytherapy in recurrent and previously irradiated head and neck cancers-preliminary results. Brachytherapy. 2007;6(2):157-63. doi: 10.1016/j.brachy.2006.12.001. [PubMed: 17434110].

21. Tselis N, Ratka M, Vogt HG, Kolotas C, Baghi M, Baltas D, et al.
Hypofractionated accelerated CT-guided interstitial (1)(9)(2)IrHDR-Brachytherapy as re-irradiation in inoperable recurrent cervical lymphadenopathy from head and neck cancer. Radiother Oncol. 2011;98(1):57-62. doi: 10.1016/j.radonc.2010.10.025. [PubMed: 21129799].

22. Kolotas C, Tselis N, Sommerlad M, Roddiger S, Schnabel T, Baltas $D$, et al. Reirradiation for recurrent neck metastases of head-andneck tumors using CT-guided interstitial 192Ir HDR brachytherapy. Strahlenther Onkol. 2007;183(2):69-75. doi: 10.1007/s00066-007-1632-2. [PubMed: 17294110]. 